\title{
REVISTAMARACANAN
}

\section{A construção da "República de Ipanema" no Rio de Janeiro dos anos 1960}

The making of the "Ipanema Republic" in Rio de Janeiro in the 1960's

\section{Andréa Cristina de Barros Queiroz*}

Universidade Federal do Rio de Janeiro

Rio de Janeiro, Rio de Janeiro, Brasil

Recebido em: 02 jan. 2020.

Aprovado em: 04 mar. 2020.

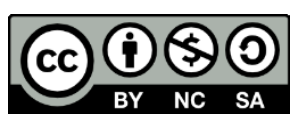

\footnotetext{
* Historiadora e Diretora da Divisão de Memória Institucional do Sistema de Bibliotecas e Informação (SiBI) da Universidade Federal do Rio de Janeiro. Doutora em História Social pela Universidade Federal do Rio de Janeiro; Mestre em História pela Universidade Federal Fluminense; graduada em História pela Universidade do Estado do Rio de Janeiro. (andreaqueiroz@sibi.ufrj.br)

ORCID iD: https://orcid.org/0000-0002-7173-375X

CV Lattes: http://lattes.cnpq.br/1838955922491509
} 


\title{
Resumo
}

Nos anos 1960, a cidade do Rio de Janeiro foi concebida a partir do ideário construído sobre a memória de uma "República Ipanemense", lócus da Zona Sul carioca onde se amalgamou uma parcela da vanguarda boêmio-literária nacional, principalmente porque o bairro foi o polo difusor de diferentes movimentos sociais, políticos e culturais que se tornaram importantes no cenário de oposição à ditadura civil-militar no país, como: a contracultura; o Cinema Novo; a Esquerda Festiva; a Banda de Ipanema e o jornal O Pasquim. Neste contexto, foi construída uma memória sobre uma Ipanema Cosmopolita em oposição a Ipanema Provinciana, ou seja, mais que um bairro carioca, era uma "República" que representava a metonímia de Brasil, que lançava moda, hábitos e costumes para outras regiões da cidade e para o país, que apesar de sua popularidade nacional, não era popular e sim bastante elitizada, ao contribuir pra disseminar a cultura do carioquismo.

Palavras-chave: Ditadura Civil-Militar. Cronistas. Rio de Janeiro. Ipanema.

\begin{abstract}
In the 1960s, the city of Rio de Janeiro was conceived from the ideas built on the memory of a "Ipanemense Republic", the locus of the South Zone of Rio de Janeiro, where a portion of the national bohemian-literary avant-garde was amalgamated, mainly because the neighborhood was the center for the diffusion of different social, political and cultural movements that have become important in the scenario of opposition to the civil-military dictatorship in the country, such as: counterculture; the "Cinema Novo"; the "Esquerda Festiva"; the "Banda de Ipanema" and the newspaper $O$ Pasquim. In this context, a memory was built on a Cosmopolitan Ipanema in opposition to Provincial Ipanema, that is, more than a neighborhood in Rio, it was a "Republic" that represented the metonymy of Brazil, which launched fashion, habits and customs to other regions of the city and for the country, which, despite its national popularity, was not popular but rather elite, as it contributed to spread the culture of carioquismo.
\end{abstract}

Keywords: Civil-Military Dictatorship. Chroniclers. Rio de Janeiro. Ipanema. 


\section{A cidade maravilhosa e a cultura do carioquismo}

A cidade do Rio de Janeiro e os cariocas foram inúmeras vezes representados por diversas gerações de cronistas que projetaram em suas prosas esses dois sujeitos: a cidade e o seu habitante. Portanto, tais cronistas ajudaram a construir e a divulgar o "modo de ser carioca" e o ideário de uma "cidade maravilhosa" principalmente na década de 1960. Dessa maneira, a análise da construção dessas duas identidades se tornou de suma importância para compreendermos o contexto de fabricação de outra identidade do Rio de Janeiro - a República de Ipanema.

Podemos dizer que a cidade do Rio de Janeiro, especialmente na década de 1960 quando se promoveu com intensidade o mito da "cidade maravilhosa" e da "cultura do carioquismo" -, era um caleidoscópio de padrões e valores culturais, línguas e dialetos, religiões e seitas, modos de vestir e alimentar, etnias e raças, problemas e dilemas, ideologias e utopias. Enfim, durante os anos 1960, o Rio de Janeiro se consagrou como o "coração do Brasil" conforme diz a letra de seu hino oficial, a marchinha de carnaval "Cidade Maravilhosa", criada em 1935 por André Filho para o concurso de marchinhas daquele ano e organizado pela Prefeitura do Distrito Federal. Ela passou a ser cantada por Aurora Miranda no encerramento dos bailes de carnaval ano após ano, e ainda hoje é com essa música que os cariocas se despedem da folia de momo. Contudo, foi somente em 1961, por decisão do então Governador do Estado da Guanabara, Carlos Lacerda, que a música se tornou o hino oficial da cidade.

Nesse contexto, podemos dizer que houve também a fabricação da "cultura do carioquismo", um tipo ideal, um cidadão-padrão da cidade do Rio de Janeiro caracterizado por sua dimensão local, mas, ao mesmo tempo nacional. ${ }^{1}$ Essa singular cidadania foi alimentada por diversos cronistas que construíram tal identidade, a ideia do carioca como "um estado de espírito: o de alguém que, tendo nascido em qualquer parte do Brasil (ou do mundo) mora no Rio de Janeiro e enche de vida as ruas da cidade", como descreveu Fernando Sabino. ${ }^{2}$ Contudo, muitos autores salientaram que essa marca estava circunscrita há uma região específica da cidade, a Zona Sul, definida na década de 1960 por uma nova territorialidade cultural e de sociabilidade, isto é, no bairro de Ipanema.

Assim, a construção da "cidadania carioca" como "estado de espírito" se perpetuou entre diversos cronistas durante décadas. O carioca, compositor e poeta da cidade, Vinícius de Moraes, escreveu na crônica "Estado da Guanabara" em 1960 que

um carioca que se preza nunca vai abdicar de sua cidadania. Ninguém é carioca em vão. Um carioca é um carioca. Ele não pode ser nem um pernambucano, nem um mineiro, nem um paulista, nem um baiano nem um amazonense, nem um gaúcho. Enquanto que, inversamente, qualquer uma dessas cidadanias, sem

\footnotetext{
${ }^{1}$ MESQUITA, Claudia. De Copacabana à Boca do Mato: o Rio de Janeiro de Sérgio Porto e Stanislaw Ponte Preta. Rio de Janeiro: Casa de Rui Barbosa, 2008.

2 SABINO, Fernando. Livro aberto. Rio de Janeiro: Record, 2001.
} 
diminuição de capacidade, pode transformar-se também em carioca; pois a verdade é que ser carioca é antes de mais nada um estado de espírito. [...] Pois ser carioca, mais que ter nascido no Rio, é ter aderido à cidade e só se sentir completamente em casa, em meio à sua adorável desorganização. ${ }^{3}$

Dessa forma, essa particular cidadania foi definida por "códigos de pertença cultural entre os de casa e os que adotaram a cidade como sua". ${ }^{4}$ Isto é, compartilhavam dessa ideia os cariocas de nascença ou não, já que também estavam incluídos nessa definição os que acolheram a cidade e foram acolhidos por ela. Entre os principais representantes dessa "cultura do carioquismo" estavam: Millôr Fernandes; Vinícius de Moraes; Sérgio Porto; Paulo Mendes Campos; Antônio Maria; Fernando Sabino; etc. Como exemplo daqueles que adotaram a cidade temos o escritor pernambucano Luís Jardim que enfatizou: "todo brasileiro que vem para o Rio carioquiza-se, e todo brasileiro que não vem não sabe o que perde". ${ }^{5}$ Portanto, compreendemos que a junção de símbolos e agências culturais produziu a construção de um "caráter carioca" que, muitas vezes, se apresentou e foi divulgado como caráter nacional.

A construção do referencial de "cidade maravilhosa" e da "cultura do carioquismo" pode ser também compreendida quando analisamos uma das principais marcas da cidade do Rio de Janeiro, quer dizer, a sua relação sócio-política e cultural com as demais cidades do país como capital da Nação e os desdobramentos da transferência da capital para Brasília em 1960.

Portanto, é necessário ressaltarmos que, em 1960, a cidade do Rio de Janeiro que deixara de ser a capital política do país, não perderia seu referencial de capitalidade, expressando ainda a ideia de "farol do Brasil", norteando costumes, valores, hábitos e expressões culturais para os brasileiros. ${ }^{6}$ A identidade do Rio de Janeiro como símbolo do Brasil fora construída desde o período do Império com suas características de capital cosmopolita (a cidade era o principal elo com o mundo europeu, estava em sintonia com o "mundo civilizado", tornando-a, assim, uma fonte de irradiação do processo civilizacional para o país) e se perpetuou ao longo da História Republicana (mesmo com as mudanças políticas, o Rio de Janeiro permaneceria como a "vitrine da nação"). Um dos grandes referenciais que comprovam essa relação metonímica entre Rio e Brasil é o fato de que mesmo deixando de ser a capital oficial, em 1960, a cidade continuaria a sediar instituições culturais de dimensões nacionais como: a Biblioteca Nacional, o Arquivo Nacional, o Museu Nacional de Belas-Artes, o Instituto Histórico e Geográfico Brasileiro, a Academia Brasileira de Letras, o Museu Histórico Nacional. ${ }^{7}$

Cabe ressaltar ainda que na década de 1960, ao mesmo tempo em que a cidade do Rio de Janeiro deixava de ser a capital federal, transformava-se em um Estado-Capital com a criação do Estado da Guanabara, em 14 de abril de 1960. Buscava-se, com isso, construir um passado para o Rio capaz de garantir ao "agora Estado da Guanabara o lugar de eterna cabeça

\footnotetext{
${ }^{3}$ MORAES, Vinícius de. Para viver um grande amor. Rio de Janeiro: José Olympio, 1984, p. 85.

4 MESQUITA, Claudia. De Copacabana à Boca... Op. cit., p. 42.

5 Apud Ibidem, p.43.

6 NEVES, Margarida de Souza. História da crônica: crônica da história. In: RESENDE, Beatriz (org.). Cronistas do Rio. Rio de Janeiro: José Olympio, 1995, p. 27.

7 MOTTA, Marly. Rio, cidade-capital. Rio de Janeiro: Zahar, 2004, p. 48.
} 
da nação". ${ }^{8}$ Assim, foi criada a imagem da Belacap com a intenção de unir duas identidades: a da ex-Cidade-Capital quatrocentona e a do mais novo Estado da federação.

Para Claudia Mesquita, a perspectiva de autonomia política da antiga cidade-capital, consolidou-se com a criação do Estado da Guanabara. Correspondeu à necessidade do estabelecimento de um novo território com uma identidade política e cultural, mobilizando personagens, marcos fundadores e mitos de origem que se associaram para formar essa "comunidade imaginada", uma "cidade maravilhosa" e um cidadão ideal forjado na "cultura do carioquismo". ${ }^{9}$ Assim, a instauração da Guanabara correspondeu à disputa em torno de símbolos que deveriam representar o novo Estado. Foi nesse momento, inclusive, que se escolheu a marchinha de carnaval "Cidade Maravilhosa" como hino oficial da cidade, como mencionado anteriormente.

A marca da capitalidade do Rio de Janeiro certamente é o elemento definidor da cidade, aquilo que a diferencia de todas as outras do país. E no momento em que a cidade se redefine no contexto federativo, também tem que se posicionar diante das antigas disputas pela hegemonia política nacional. Assim, seus intelectuais e cronistas tiveram um papel fundamental no que tange à construção da imagem do carioca como síntese dessa brasilidade.

Nesse contexto, destacamos também a posição de destaque da cidade do Rio de Janeiro diante do cenário turbulento dos intensos movimentos sociais, políticos e culturais durante o golpe de 1964 e que se perpetuou ao longo regime civil-militar (1964-1985). Segundo Roedel, o Rio de Janeiro ocupou uma posição hegemônica ao promover grandes manifestações, tanto de oposição quanto de apoio ao regime militar. Esses acontecimentos ganharam projeção nacional. E nesse sentido, apesar de não ser mais a capital federal, a cidade prosseguiu, de forma significativa, alterando hábitos, lançando modas, interferindo e reorientando costumes. A sua posição no imaginário nacional possibilitou que as mobilizações, nos planos político e cultural, "fossem propagadas pelo país com maior facilidade do que se partissem de outras regiões do Brasil". ${ }^{10}$

Podemos dizer que a transferência da capital para Brasília em 1960, a renovação técnica da imprensa brasileira durante a década de 1950 e, por fim, o auge da crônica como gênero literário foram os fatores determinantes que, associados, fizeram dessa época um marco inaugural na história da cidade formando identidades e tradições culturais processadas pelos cariocas e pelos não-cariocas. ${ }^{11}$

A crônica como gênero literário possui uma identidade urbana carioca. Como ressaltou Beatriz Resende, a crônica "nasceu, cresceu e se fixou no Rio". ${ }^{12}$ Os cronistas foram os principais intérpretes da cidade resignificada e de seu cidadão ideal. As suas narrativas favoreceram a fixação do mito de "cidade maravilhosa" e foi ratificada pelo crescimento da

\footnotetext{
${ }^{8}$ MOTTA, Marly. Rio, cidade-capital. Op. cit., p. 2.

9 MESQUITA, Claudia. De Copacabana à Boca... Op. cit., p. 38.

${ }^{10}$ ROEDEL, Hiran. Uma cidade de muitos lugares. In: VIEIRA, A. da C. (org.). Rio de Janeiro: panorama sociocultural. Rio de Janeiro: Ed. Rio, 2004, p. 41.

${ }^{11}$ MESQUITA, Claudia. De Copacabana à Boca... Op. cit., p. 19.

12 RESENDE, Beatriz (org.). Cronistas do Rio. Rio de Janeiro: José Olympio, 1995, p. 35.
} 
imprensa no Brasil, contribuindo, dessa forma, para a divulgação das "coisas do Rio": a exaltação de suas belezas naturais, de suas mulheres e de seu cosmopolitismo.

A maioria dos cronistas dessa geração dos anos 1960 construiu uma representação da cidade, ou melhor, uma identidade do Rio de Janeiro enquanto metonímia do Brasil em suas narrativas. Como salientou Margarida de Souza Neves, "cronistas, por um lado, apresentam cotidianamente o particular relevo desta cidade capital e, por outro, reiteram um deslizamento discursivo expressivo da capitalidade do Rio de Janeiro, já que, em seus textos, muitas vezes Brasil e Rio de Janeiro são termos intercambiáveis". ${ }^{13}$

Lembramos que o mito construído em torno da cidade como "maravilhosa" não foi compartilhado por todos os cronistas daquele período. De um lado, havia os que acreditavam na construção da "cidade ideal", impregnada pelo mito de "cidade maravilhosa": bela, cordial, alegre, cosmopolita e única, onde o olhar se fixava na Zona Sul da cidade. Por outro lado, aqueles que ajudaram a edificar a "cidade real", um universo distante da zona litorânea e cordial, e presente apenas nas crônicas policiais, localizada na Zona Norte: com personagens vulgares, trágicos e infames, longe dos sujeitos com cabelos ao vento e com os corpos dourados do sol de Ipanema, Leblon ou Copacabana. Como, por exemplo, Sérgio Porto e Paulo Mendes Campos que se sentiram exilados na chamada "República de Ipanema" e com suas crônicas voltavam-se para o ambiente e para a descrição de personagens do subúrbio carioca. Ou ainda, enquanto muitos cronistas se esforçaram por exaltar a Belacap - a cidade ideal; Stanislaw Ponte Preta (1962) - heterônimo de Sérgio Porto - satirizava-a, mostrando a cidade real, denunciando os buracos de suas ruas, nomeando-a de Buracap. ${ }^{14}$

Para Angel Rama, a "cidade real" correspondia à ordem física, sensível, material, e está submetida aos vaivéns da construção e destruição; já a "cidade ideal" refere-se à construção simbólica assegurada pelo universo dos signos, que conta com a cidade das letras para ordená-lo. ${ }^{15}$ Assim, a cidade real era a vida concreta do dia-a-dia, dos conflitos, que se expande com uma anarquia e que a cidade ideal quer domar. ${ }^{16}$ Ou como argumentou Giulio Argan, "a cidade ideal nada mais é que um ponto de referência em relação ao qual se medem os problemas da cidade real, a qual pode, sem dúvida, ser concebida como uma obra de arte, que no decorrer de sua existência, sofreu modificações, alterações, acréscimos, deformações, às vezes verdadeiras crises destrutivas". ${ }^{17}$

Lúcia Rito analisou que a cidade do Rio foi dividida por Zonas muito mais pelos jornais e pela mídia do que nos arquivos oficiais. Segundo a autora, a expressão Zona Norte também pouco aparecia nos principais livros sobre a história do Rio de Janeiro até a década de 1960, e quando era mencionada, a sua referência era expressa como sendo uma imensa fatia que se estendia dos bairros encontrados depois do Túnel Rebouças e da Praça da Bandeira, até os da área da Central do Brasil e da Leopoldina, o chamado subúrbio carioca. Portanto, a

\footnotetext{
13 NEVES, Margarida de Souza. História da crônica... Op. cit. , p. 26.

14 MESQUITA, Claudia. De Copacabana à Boca... Op. cit.

15 RAMA, Angel. A cidade das letras. Rio de Janeiro: Brasiliense, 1985, p. 29.

16 Ibidem, p. 110.

17 ARGAN, Giulio Carlo. História da arte como história da cidade. São Paulo: Martins Fontes, 2005, p. 73.
} 
demarcação da Zona Norte e da Zona Sul como lados opostos da mesma cidade foi uma ação meramente cultural, já que os pesquisadores sobre o tema não encontraram referências que justificassem essa demarcação espacial. ${ }^{18}$ Dessa maneira, compreendemos que essa fragmentação do espaço se desenvolveu a partir da visão elitizada por grande parte dos cronistas ipanemenses, principalmente nas décadas de 1960 e 70, os quais projetaram para o Rio de Janeiro e para o Brasil os valores e os comportamentos da chamada "República de Ipanema".

Como destacou Paulo Francis, a intelligentsia ipanemense temia "que as areias então muito brancas do Leblon e Ipanema fossem maculadas não só por frangos e farofas, mas pelo pessoal da Zona Norte, pessoas que não pertenciam à aristocracia da Zona Sul". ${ }^{19}$ Dessa forma, a divisão entre Zona Norte e Zona Sul foi estratégica e simbolicamente representadas, posteriormente às criações desses cronistas, pela construção do Túnel Rebouças, inaugurado no governo de Carlos Lacerda, em 1967, com isso, o que deveria facilitar e encurtar distâncias, acabou por concretizar tal segregação.

Enfim, o bairro de Ipanema teve um significado importante na construção da história da cidade do Rio de Janeiro, na década de 1960, e os seus cronistas foram os atores privilegiados na construção dessa narrativa. Por tudo isso, faz-se necessário uma compreensão dos elementos constitutivos dessa República de Ipanema.

\section{A República de Ipanema e o seu modus vivendi}

\subsection{Ipanema provinciana}

O bairro de Ipanema possui 1,67 quilômetros quadrados. Seu território consiste em uma estreita faixa de terra, de formato quase retangular, banhada ao sul pelo oceano Atlântico e ao norte pela Lagoa Rodrigo de Freitas. Em comparação com a maioria dos bairros do Rio de Janeiro, Ipanema pode ser classificada como pequena. No entanto, suas dimensões espaciais não são proporcionais às construções simbólicas que se desenvolveram entre os cronistas da segunda metade do século XX.

Contudo, para podermos compreender tais construções simbólicas, é preciso a priori entendermos a sua gênese histórica. Em 1894, fundou-se o projeto de construção da Villa de Ipanema. O Barão de Ipanema, José Antonio Moreira Filho, foi o responsável por transformar o imenso areal no mais novo bairro da cidade. O nome Ipanema foi dado em homenagem ao seu pai, José Antonio Moreira, primeiro Barão, Visconde e Conde de Ipanema. Para a implementação da Villa de Ipanema foi necessário que o Barão criasse um foco de atração para o local para a venda de terrenos, por isso que em 1883 ele organizou uma empresa urbanística que seria utilizada nessa empreitada. Em 1905, após a morte do segundo Barão de

18 RITO, Lúcia; SOUZA, Jair de (org.). Zona norte: território da alma carioca. Rio de Janeiro: Norte Shopping, 2001, p. 25.

${ }_{19}$ Apud MESQUITA, Claudia. De Copacabana à Boca... Op. cit., p. 141. 
Ipanema, foi criada a Companhia Construtora Ipanema que ficou responsável pela continuidade das obras, e à medida que o bairro se urbanizava, ganhava novos moradores, começando, com isso, a aparecer os primeiros estabelecimentos comerciais.

Atrelado a isso, a linha oficial de bonde chegou a Ipanema em 1902, ainda movida à tração animal; e em 1903, foram inaugurados os bondes elétricos, fator importante para a venda de mais terrenos em Ipanema. A partir de 1923, os bondes foram sendo substituídos pelos ônibus, mas aqueles ainda circulariam até $1963 .^{20}$

Em muitas crônicas produzidas ao longo do século $X X$, o passado de Ipanema fora rememorado com características de uma cidade de interior, já que seu reduzido número de habitantes fazia com que todos se conhecessem e participassem um do cotidiano do outro. Assim, em muitos textos o termo "provinciano" apareceu como representação dessa Ipanema antiga, anterior ao mítico momento do final dos anos 1960 e dos 70, descrita por muitos cronistas como o ponto culminante da "Ipanema clássica", período conhecido também como o da criação da "República de Ipanema".

Para alguns autores, o passado provinciano de Ipanema não se desfez totalmente, eles consideraram que se mesclou à nova Ipanema, a cosmopolita, sobretudo nos anos 1960, como definiu Ruy Castro, Ipanema era uma "Província de cosmopolitas", ainda pequena no tamanho onde todos se conheciam, mas enorme nas suas simbologias. ${ }^{21}$

Essa síntese sobre a história de Ipanema caracterizada por uma gênese provinciana, no início do século XX, acabou por interagir com o cosmopolitismo que assolou as suas ruas e os hábitos daqueles que ali circulavam a partir dos anos 1960. Tanto que alguns cronistas apresentaram dúvidas ao falar de Ipanema, ora exaltavam seu passado provinciano, ora se deleitavam com a vanguarda cultural de seu cosmopolitismo. Por exemplo, no livro de memórias sobre o bairro que Jaguar produziu, o cronista promoveu várias indagações sobre qual Ipanema ele estaria se referindo:

Ipanema era uma província? Era. Pelo menos está dito e repetido nos livros e crônicas que falam do bairro. Era um lugar família, mas a sacanagem rolava solta. Era um lugar pacato, podíamos assistir à corrida de submarino fazendo contorcionismo nos fuscas, e andar pelo calçadão de madrugada sem sermos assaltados por pivetes. [...] Então, de que Ipanema vou falar? Da familiar ou da libertina? Da provinciana ou da cosmopolita? Da bairrista, da agregadora ou da muito pelo contrário? ${ }^{22}$

Para Marisol Valle o "provincianismo" atribuído ao passado de Ipanema foi apresentado por muitos cronistas como portador de qualidades sui generis, ou seja, opostas ao tradicionalismo normalmente identificado nas pequenas cidades. Dessa forma, havia uma condição ambígua nessa representação sobre Ipanema, porque se atribuíram, ao mesmo

${ }^{20}$ BALSA, Marilene. Ipanema de rua em rua. Rio de Janeiro: Ed. Rio; Universidade Estácio de Sá, 2005, p. 11-30.

21 CASTRO, Ruy. Ela é carioca: uma enciclopédia de Ipanema. São Paulo: Companhia das Letras, 1999, p. 11.

22 JAGUAR. Ipanema: se não me falhe a memória. Rio de Janeiro: Relume-Dumará, 2000, p. 11-18. 
tempo, elementos tipicamente associados às cidades pequenas - como as relações de sociabilidades primárias - com aspectos vanguardistas das cidades cosmopolitas. ${ }^{23}$

\subsection{Ipanema Cosmopolita}

Assim como a década de 1950 representou para a história da cidade o auge do bairro de Copacabana, com a efervescência da boemia da Bossa Nova, as décadas de 1960 e 1970 representaram não somente a notoriedade de Ipanema, mas, acima de tudo, a disseminação de seu modus vivendi para a cidade, para o país e para o mundo. Ipanema se tornou a partir daquele momento um bairro cosmopolita e os cronistas foram os principais agentes para a disseminação dessa ideia. Com a contribuição de suas narrativas perpetuou-se na memória dos habitantes da cidade do Rio de Janeiro que Ipanema representava um paradigma de vanguarda cultural, não apenas local, mas, sobretudo, nacional.

O cosmopolitismo de Ipanema também serviu como pano de fundo para outra representação bastante frequente sobre o bairro, isto é, a de um lugar que "lança modas". De acordo com Marisol Valle, a concepção de "moda" utilizada para qualificar Ipanema não se relacionava somente ao sentido mais comum de inovações nas vestimentas ou nos acessórios de uso pessoal, envolvia outros significados. A associação entre Ipanema e a moda fundamentou-se na ideia de que o "ipanemense típico possuía forte gosto pelo novo e uma habilidade peculiar em transgredir, criar manifestações artísticas e culturais, estilos de vida, comportamentos e atitudes". ${ }^{24}$

Segundo o jornalista Ruy Castro, o grande caldo cultural que simbolizou Ipanema na década de 1960 nasceu no Arpoador. ${ }^{25}$ O "principado do Arpoador" como se perpetuou na memória daqueles que ali estiveram ou dos que almejavam frequentar era um lugar pequeno dentro da cosmopolita "República de Ipanema", ou seja, possuía a dimensão realmente de um principado que abarcou diferentes turmas e culturas. ${ }^{26}$

Em 1963, o Arpoador era "o grande laboratório de costumes da cidade". Foi neste lugar, que "as primeiras meninas brasileiras se atreveriam a usar biquíni, [...] era o duaspeças com o umbigo à mostra, [...] e em poucos verões, os biquínis estariam revelando também a beleza das meninas de família de Ipanema". ${ }^{27}$

A mestiçagem cultural marcou Ipanema e se espraiou para além da orla e penetrou nos antigos bares do bairro, como: o Jangadeiro, o Zeppelin, o Veloso e o Mau-cheiro. Os bares de Ipanema estruturaram uma grande rede de sociabilidade que penetrou nos hábitos da cidade. Eles se transformaram em palco perfeito para o encontro de diferentes gerações de artistas,

\footnotetext{
23 VALLE, Marisol Rodriguez. A província da ousadia: representações sociais sobre Ipanema. 2005. Dissertação (Mestrado em Sociologia) - Universidade Federal do Rio de Janeiro, Rio de Janeiro, p. 14.

${ }^{24}$ Ibidem, p. 15.

25 Denomina-se Arpoador a extremidade esquerda da praia de Ipanema, que termina junto à Rua Francisco Otaviano, marco inicial da praia de Ipanema no início do século XX. BALSA, Marilene. Ipanema de rua... Op. cit., p. 59.

${ }^{26}$ CASTRO, Ruy. Ela é carioca... Op. cit., p. 12.

${ }^{27}$ Ibidem, p. 40.
} 
intelectuais, jornalistas e pessoas comuns que se reuniam e se apraziam com o "papo" descontraído e uma bebida gelada após um dia ensolarado na praia. ${ }^{28}$

Para muitos jornalistas que seguiram a tradição boêmia da Lapa e posteriormente de Copacabana, os bares de Ipanema eram "os melhores fóruns de debate", onde se podia encontrar os amigos e discutir questões relativas ao cotidiano, à política, à sociedade, à cultura ou, simplesmente, como se diz no Rio: "jogar conversa fora". Como destacou Millôr Fernandes: "basta ouvir pra ver que o nervo de todas as conversas cariocas, a do bar sofisticadíssimo, a do living-room granfa, a da cama (antes e depois) é o humor, a crítica, a piada e a graça, o descontraimento". ${ }^{29}$

Por tudo isso, muitos movimentos culturais se difundiram entre os descontraídos e por vezes acalorados debates nessas mesas de bar, como o Cinema Novo. Segundo Marisol Valle, os bares de Ipanema foram classificados pelos jornais de época conforme o seu tipo específico de público. Assim, de acordo com tal tipologia, os escritores e os jornalistas se reuniam no Zeppelin; os músicos no Veloso; o Jangadeiro era o reduto da Banda de Ipanema; e o MauCheiro era o pé-sujo frequentado pelo pessoal do Cinema Novo. Todavia, isso não quer dizer que um grupo não pudesse circular pelos demais bares, promovendo uma grande sociabilidade. ${ }^{30}$

A relação do Cinema Novo - definido por muitos intelectuais como "vanguarda estética e ideológica da produção cultural brasileira" ${ }^{31}$ - com os espaços informais dos botecos, cujos principais representantes eram de Ipanema, gerou uma produção simbólica de ligar o nome do movimento ao bairro. Para Valle, os bares de Ipanema não teriam servido apenas como áreas de lazer e de sociabilidade aos jovens cineastas brasileiros. Representariam, acima de tudo, o espaço onde se desenvolveram as ideias e os principais conceitos da nova estética do cinema nacional. ${ }^{32}$

Dentre essas manifestações também estava a Bossa Nova, que apesar de ter surgido, em 1959, em Copacabana, logo se popularizou entre os jovens de classe média da Zona Sul do Rio e no meio universitário. Dessa maneira, o movimento teve seu apogeu em Ipanema ao longo da década 1960. Cabe salientar que a imagem de Ipanema associada à Bossa Nova ficou imortalizada na canção Garota de Ipanema de Tom Jobim e Vinícius de Moraes. Mas, ao contrário do que muitos rememoram, a canção não foi composta nas mesas do Bar Veloso, apesar de ser este o principal reduto dos autores da música e deste lugar terem avistado a sua musa inspiradora, a jovem Heloísa Eneida. Entretanto, ela foi composta por Tom em seu apartamento na rua Barão da Torre, 107, no verão de 1962, e a letra por Vinícius em sua casa em Petrópolis semanas depois. O interessante é que a famosa canção, que consagrou o bairro,

\footnotetext{
${ }^{28}$ A coloquialidade típica desse período lançou novos padrões sociolinguísticos que foram apropriados não somente pelos frequentadores do bairro, mas por toda cidade. Um dos principais difusores dessa nova fala ipanemense foi o jornal alternativo $O$ Pasquim.

29 FERNANDES, Millôr. A história é uma história: e o homem é único animal que ri. Porto Alegre: L\&PM, 1978, p. 51.

30 VALLE, Marisol Rodriguez. A província da ousadia... Op. cit., p. 23.

${ }^{31}$ HOLLANDA, Heloísa Buarque de; GONÇALVES, Marcos. Cultura e participação nos anos 60. São Paulo: Brasiliense, 1999, p. 49.

32 VALLE, Marisol Rodriguez. A província da ousadia... Op. cit., p. 25.
} 
foi lançada apenas em outono do mesmo ano, na vizinha Copacabana, na Boate Au Bon Gourmet no show O Encontro, com Tom, Vinícius, João Gilberto e Os Cariocas. Como observou Ruy Castro, Copacabana era o "local de trabalho dos bossa-novistas, uma vez que era lá que ficavam o Beco das Garrafas e as demais boates. Assim, a Bossa Nova ia a Copacabana para trabalhar. E para morar, criar e se divertir, seu território era Ipanema".33

Certamente, os bares de Ipanema, ainda hoje, são um dos pontos altos de sociabilidade do bairro, depois da manhã ensolarada de atividades na praia, como: as caminhadas no calçadão, o futebol de areia ou o jogo de frescobol, que foi importado de Copacabana junto com os novos moradores. Foram inúmeros os sujeitos que projetaram em seu cotidiano a praia e o bar como elementos definidores não somente da identidade de Ipanema, mas d'alma do Rio, do jeito carioca. ${ }^{34}$

Dessa forma, começamos a delinear esse território, não somente pelo sentido geográfico, mas, sobretudo, no âmbito de sua cultura e de suas práticas sociais, que ficou conhecido como a "República de Ipanema", principalmente nas décadas de 1960 e 70 . Essa República foi composta por diferentes turmas, dentre elas destacamos, a priori, os remanescentes da tradicional boemia literária dos anos 1940 e 50 da suplantada Copacabana, mas, acima de tudo, a nova geração de cronistas que elegeram o hábito do "whiskyzinho" ao cair da tarde, num desses bares anteriormente mencionados, como o referencial simbólico que definiria esse grupo nessa nova territorialidade boêmia, isto é, na "República de Ipanema".

Segundo Claudia Mesquita essa geração de boêmios ipanemenses destronou a antiga "República dos Estados Unidos de Copacabana", assim chamada pelo cronista Henrique Pongetti. Para a historiadora, foi graças ao investimento de uma geração de intelectuais cariocas e da força da imprensa renovada que o bairro de Ipanema começou a suplantar Copacabana como estética dominante da Zona Sul da cidade. ${ }^{35}$

Na década de 1960, em muitas crônicas, os jornalistas Jaguar, Paulo Francis e Carlinhos de Oliveira consagraram a assertiva de que "intelectual não vai à praia, intelectual bebe" como marca registrada dessa turma de Ipanema. Posteriormente, já na década de 1970, esse tipo de intelectual ficou conhecido como Chopnic, termo criado por Jaguar e Ivan Lessa n'O Pasquim para uma propaganda de cerveja no jornal, e depois foi atribuído àquelas figuras de Ipanema que quase sempre não chegavam até a praia, pois paravam antes num bar das proximidades para beber e encontrar os amigos, por isso que "um chopnic sequer chegava à areia da praia". ${ }^{36}$

Contudo, é válido dizer que não eram todos os cronistas que conjugavam dessa afirmação, como Millôr Fernandes, um ilustre representante dessa nova "República", que se manteve fiel aos seus antigos hábitos adquiridos quando ainda era morador da cosmopolita

\footnotetext{
33 CASTRO, Ruy. Ela é carioca... Op. cit., p. 57.

${ }^{34}$ ARRUDA, Phrygia. O jeito carioca de ser: entre a tradição e a modernidade: o imaginário de um Brasil moderno. 2002. Tese (Doutorado em Psicologia) - Universidade Federal do Rio de Janeiro, Rio de Janeiro, p. 117.

${ }^{35}$ MESQUITA, Claudia. De Copacabana à Boca... Op. cit., p. 147.

${ }^{36}$ REGO, Norma Pereira. Ipanema dom divino. Rio de Janeiro: Nova Fronteira, 1983, p. 76.
} 
Copacabana nas décadas anteriores. Ele pertenceu à "geração sportman" e se vangloriava de ser um dos inventores do jogo de frescobol nas areias de Copacabana. Como ele mesmo declarou ao ser perguntado onde se reuniam os escritores da sua geração: "o canto nosso era nos bares. Eu e Sérgio Porto íamos à praia. [...] Ele era um trabalhador braçal e levava uma cestinha de jornal para ler, enquanto eu preferia jogar frescobol". ${ }^{37}$

Nessa singular "República", criou-se também a ideia da multidisciplinaridade do sujeito: escritores faziam cinema, arquitetos faziam música, cartunistas faziam teatro, pescadores faziam fotografia e muitos faziam quase tudo isso. E como todos naquele ambiente se sentiam "intelectuais" ou "artistas", os artistas e intelectuais de verdade "podiam locomover-se sem embaraços naturais da fama". Enfim, essa mistura definiu os sujeitos da "República de Ipanema", "uma província habitada por cosmopolitas e uma moderna Shangri-lá à beira-mar, com uma qualidade de vida que é difícil de acreditar". ${ }^{38}$

Todavia, é preciso ressaltar que apesar desse encantamento com o espaço e do cosmopolitismo da "República de Ipanema", nem todos os cronistas remanescentes da geração de boêmios de Copacabana se sentiram pertencentes a essa nova territorialidade. Sérgio Porto, por exemplo, se sentia um exilado nesse novo território cultural. Ele recriava em suas crônicas os devaneios de sua demolida Copacabana, ou se refugiava no cenário esquecido dos subúrbios cariocas com seus diversos personagens retratados na intimidade. Para Cláudia Mesquita, Sérgio Porto foi um intérprete privilegiado desses deslocamentos e ambiguidades, sendo ele próprio o resultado desses conflitos, como também um dos raros intelectuais de sua época a apontar os perigos de uma cidade cada vez mais tomada pelo preconceito em relação às classes mais pobres e submetida à hegemonia da Zona Sul. Podemos citar a sua desconstrução de um dos ícones dessa "República", isto é, as garotas que iam "num doce balanço a caminho do mar". ${ }^{39}$

A garota de Ipanema de Sérgio Porto nada se assemelhava com a clássica Garota idealizada por Vinicius de Moraes e Tom Jobim. O cronista retratou "o lado sombrio das meninas de Ipanema, cheias de futilidades, excessivas preocupações com a aparência e um vazio existencial, compensado por uma vida noturna intensa, frívola e com muitos vícios". ${ }^{40}$

Porto destacava em suas crônicas um distanciamento da garota "bossa-nova" que tanto encantou Tom, Vinícius e outros cronistas da época, que se apraziam com os símbolos dessa Ipanema idealizada: a praia ensolarada, os bares e as suas garotas de biquíni ou minissaia, douradas do sol, com os cabelos ao vento a caminho do mar.

O interessante dessa construção sobre a "garota de Ipanema" é que a sua primeira e famosa representante Helô Pinheiro (Heloisa Eneida Menezes Paes e Pinto) não era uma ipanemense típica dos anos 1960. Nascida na Zona Norte, no bairro do Grajaú, mudou-se aos 10 anos para Ipanema com a sua mãe (funcionária pública) que havia se separado de seu pai, o general Juarez Paes Pinto (militar que posteriormente se tornou o segundo censor d'O

\footnotetext{
37 FERNANDES, Millôr. [Entrevista]. EntreLivros, São Paulo, n. 5, set. 2005, p. 24.

${ }^{38}$ CASTRO, Ruy. Ela é carioca... Op. cit., p. 13.

39 MESQUITA, Claudia. De Copacabana à Boca... Op. cit., p. 262.

${ }^{40}$ Ibidem, p. 148.
} 
Pasquim). Apesar de ter se tornado a Garota de Tom e Vinícius aos 19 anos, foi criada para se casar virgem, ser uma boa esposa e ter filhos aos moldes tradicionais da classe média tijucana e adjacências. ${ }^{41} \mathrm{E}$ assim o fez, contrariando a postura mais moderna das moças de sua geração, que eram independentes e possuíam vida sexual ativa. Enfim, essa Garota de Ipanema na vida real não representava a vanguarda e o cosmopolitismo de Ipanema, ao invés disso, reforçava a projeção da tradicional família brasileira aos moldes míticos da moça "bela, recata e do lar". Seja como for, Helô Pinheiro representou para os seus compositores a figura da musa que é bela no sentido de apenas inspirar o homem triste e melancólico, como é salientado na música: "como estou tão sozinho, ah, porque tudo é tão triste".

A efervescência desses novos padrões de comportamento tornou Ipanema um reduto não organizado de manifestações de oposição ao status quo no pós-1964. Há uma construção fortemente disseminada por aqueles que pertenceram à "República de Ipanema" que ali se encontrava a vanguarda cultural e política do Rio de Janeiro nas décadas de 1960 e 1970, contudo, para muitos setores da esquerda e da direita daquele período, essa turma ficou conhecida pejorativamente ou não como "esquerda festiva". Essa expressão foi bastante disseminada tanto pelos militantes de esquerda quanto pela direita para caracterizarem o tipo de oposição que muitos intelectuais, artistas, cronistas, cartunistas, entre outros manifestavam para criticar o regime autoritário. E com o termo "esquerda festiva" desqualificavam o trabalho desses diversos profissionais. Percebendo-os, sobretudo os jornalistas d'O Pasquim, como um grupo que só se preocupava com festas, bebidas e mulheres. $E$, ainda entendiam que o humor e a ironia utilizados por muitos desses jornalistas eram realizados muito mais pelo lirismo do que pela denúncia ou oposição.

A "esquerda festiva", alvo de muitas críticas da própria esquerda, foi assim definida pela primeira vez na crônica do escritor Carlos Leonam, em 1963. Era composta pelos frequentadores assíduos das areias, dos bares e das festas de Ipanema. Segundo Leonam, "ela circulava em um espaço demarcado que abrangia a Zona Sul do Rio de Janeiro, cenário conhecido como cidade maravilhosa, onde não haveria pobres nem miséria, e por vezes parte de seus integrantes perambulavam até o Centro da cidade". ${ }^{42}$

Entre os principais representantes da "esquerda festiva" estavam: o poeta Ferreira Gullar, o cineasta Leon Amoedo, a produtora Tereza Aragão, os jornalistas Zuenir Ventura, Milton Temer e Norma Pereira Rego, o filósofo Leandro Konder, o publicitário Darwin Brandão, a artista plástica Marilia Kranz e alguns representantes da patota d'O Pasquim, como Ziraldo e Jaguar. Segundo Ruy Castro, "nem que fossem em espírito, eram todos ligados ao antigo Partidão, a ponto de Millôr Fernandes (que não pertencia ao grupo) tê-los classificados de PCI - Partido Comunista de Ipanema. E o seu braço armado era a Banda de Ipanema". ${ }^{43}$

A Banda de Ipanema foi idealizada poucas semanas antes do carnaval de 1965, por Jaguar, Albino Pinheiro, Ferdy Carneiro e mais trinta nomes que não somente contribuíram

\footnotetext{
${ }^{41}$ A Tijuca é um bairro da Zona Norte do Rio de Janeiro, representado por uma classe média tradicional, inúmeras vezes retratada nas crônicas e dramaturgia de Nelson Rodrigues.

42 LEONAM, Carlos. Os degraus de Ipanema. Rio de Janeiro: Record, 1998, p. 48.

${ }^{43}$ CASTRO, Ruy. Ela é carioca... Op. cit., p. 117.
} 
para a sua fundação - como: os artistas plásticos Hélio Oiticica e Hugo Bidet, os cineastas Glauber Rocha e Hugo Carvana, o fotógrafo Paulo Góes, o pintor Vergara, o cartunista Ziraldo, os cronistas Carlinhos Oliveira e Zózimo Amaral - mas, a transformaram em um acontecimento cultural, pois tornou-se um dos mais famosos blocos do carnaval carioca, conhecido internacionalmente. Salientamos também que entre seus fundadores constavam muitos dos jornalistas d'O Pasquim, periódico que se tornou a voz de Ipanema. Assim, a Banda era um "arco-íris político" ou uma "salada ideológica". ${ }^{44} \mathrm{~A}$ idade média dos fundadores era em torno dos trinta a quarenta anos. Já as mulheres não se destacaram como fundadoras, mas como musas, em especial, a atriz Leila Diniz e as escritoras Danuza Leão e Marina Colasanti. Isso também destaca a cultura política característica dessa geração que observavam as mulheres não como protagonistas, mas como coadjuvantes, ou ainda apreciadas apenas pelo apelo sexualizado. Vale destacar que apesar de serem consideradas apenas como musas pelos homens fundadores, muitas dessas mulheres transgrediram a postura conservadora e usavam seu corpo e as formas de se apresentarem em público como um ato de libertação feminina.

Nascida no primeiro Carnaval depois do golpe civil-militar de 1964, a Banda de Ipanema congregou todos aqueles que o novo regime observava como "inimigos potenciais", ou seja, todos que sofreram algum tipo de censura: jornalistas, escritores, cineastas, músicos, artistas plásticos, cartunistas. Ela possuía uma das principais características da folia de momo: a "carnavalização do poder" através do deboche e da irreverência, fazia críticas sempre bemhumoradas contra o governo e contra todos que apoiavam a ditadura, marca típica inclusive dos jornalistas d'O Pasquim que também participaram da Banda. ${ }^{45}$ Para Jaguar, "a Banda de Ipanema foi, realmente, a origem de uma série de coisas, inclusive d'O Pasquim. Foi um negócio que houve em torno de Ipanema, que a Banda de Ipanema foi a origem de tudo". ${ }^{46}$

Em virtude dessa irreverência, os sujeitos da Banda, também conhecidos por "esquerda festiva", estiveram não apenas sob a mira dos militares, foram igualmente patrulhados pela esquerda "dita séria". Uma vez que essa acreditava ser uma heresia brincar o carnaval com milhares de pessoas sendo perseguidas e torturadas pela ditadura. Já os militares e os seus mecanismos de repressão que eram, muitas vezes, o alvo predileto das irreverentes críticas dos membros da Banda, fizeram com que esses sujeitos fossem investigados pelo Serviço Nacional de Informação.

Outra marca registrada do bairro de Ipanema foi o jornal alternativo O Pasquim. 0 semanário, que possuía formato tabloide, surgiu em 26 junho de 1969 como um jornal de bairro que rompeu os limites territoriais da nova zona boêmia do Rio. Estabeleceu com o seu público um diálogo sobre as questões políticas e culturais daquele momento, apresentou uma oposição ao regime ditatorial brasileiro e, em especial, analisou os comportamentos sociais da classe média, da qual muitos de seus jornalistas eram originários, além disso, acompanhou em suas páginas a imensa transformação urbana na cidade.

\footnotetext{
${ }^{44}$ CASTRO, Ruy. Ela é carioca... Op. cit., p. 48.

45 BAKHTIN, Mikhail. A cultura popular na Idade Média e no Renascimento: o contexto de François Rabelais. São Paulo: Hucitec, 1987.

46 JAGUAR. O Pasquim, Rio de Janeiro, n. 141, mar. 1972.
} 
Muitos de seus jornalistas não eram cariocas, mas na confluência de trajetórias distintas construíram um jornal a partir das referências daquele microcosmo, lugar no qual a maioria residia e com o qual se identificava, pois eram "cariocas ipanemenses de espírito". Fazendo desse jornal uma singularidade dentre tantos surgidos naquele período, cerca de 150 durante a ditadura civil-militar brasileira. ${ }^{47}$ Seja como for, as páginas do jornal estavam recheadas da coloquialidade tipicamente ipanemense. O periódico modificou a linguagem jornalística ao reproduzir, na forma escrita ou gráfica, a oralidade, e isso acabou por influenciar a propaganda, como também transformou a fala coloquial. Dessa forma, O Pasquim deixou de ser apenas um jornal de bairro e se tornou um representante da fala nacional. Com isso, o periódico marcou não apenas a sua época, mas também toda uma geração, que passou a ser conhecida como "Geração Pasquim". 48

Ao falarmos da "República de Ipanema" não podemos deixar de analisar a juventude que circulou por um dos cenários mais importantes do bairro: a praia. Lócus que ainda hoje é o elo aglutinador de diferentes turmas, espaço privilegiado de sociabilidade e de vanguarda.

De acordo com Gilberto Velho, a ideia de ser "vanguarda" aparece como um valor fundamental para as camadas médias da Zona Sul do Rio de Janeiro, sobretudo, para os jovens das décadas de 1960 e 70. Segundo o autor, esse grupo apresentaria forte anseio por mostrar um estilo de vida "vanguardista" que se traduziria no valor atribuído ao tema da mudança como um modo de se opor a uma visão de mundo tradicional e conservadora. ${ }^{49}$

A praia de Ipanema, portanto, foi o palco principal dessa mudança de comportamento, em especial no que se refere às grandes inovações nos trajes de banho femininos, o que correspondeu à quebra de uma série de paradigmas. Lembramos que essa praia começou a ser frequentada na década de 1930, quando as normas rígidas da sociedade foram abrandadas e famílias inteiras passaram a tomar seu banho de mar. Esse novo comportamento social refletiu diretamente nos hábitos e padrões estéticos dos sujeitos, sobretudo, das mulheres, que inicialmente cobriam quase o corpo todo, depois passaram a usar os maiôs e os "duaspeças" na década de 1950, os biquínis na década de 1960, as tangas nos anos 1970, o "asadelta" e o "fio-dental" nos anos 1980, e assim por diante. Enfim, Ipanema se consagrou não apenas ao lançar a sua moda praia para o Brasil e para o mundo, mas principalmente por romper com padrões culturais moralistas da sociedade brasileira.

Para Marisol Valle, a construção simbólica de Ipanema como um bairro que "lançou moda" e que se consolidou como vanguarda dos costumes e das manifestações artísticas e culturais brasileiras pode ser edificada por uma associação entre espaços e pessoas. Segundo a autora, Ipanema deve ser entendida como um bairro onde se desenvolveram

\footnotetext{
${ }^{47}$ KUCINSKI, Bernardo. Jornalistas e revolucionários: nos tempos da imprensa alternativa. São Paulo: Ed. USP, 2003.

${ }_{48}$ QUEIROZ, Andréa Cristina de Barros. O Pasquim: um jornal que só diz a verdade quando está sem imaginação (1969-1991). 2005. Dissertação (Mestrado em História) - Universidade Federal Fluminense, Niterói (RJ).

${ }^{49}$ VELHO, Gilberto. Nobres e anjos: um estudo sobre tóxicos e hierarquia. Rio de Janeiro: FGV Ed., 1998.
} 
comportamentos pioneiros e foi no espaço da praia - mais propício para a exposição corporal que novas moralidades ganharam um destaque público. ${ }^{50}$

Por falar no espaço da praia, devemos observar os verões de Ipanema como o grande momento de divulgação do modus vivendi do bairro. Sobretudo, os verões de 1970 a 73, que representaram o auge das manifestações de contracultura para a juventude que frequentou 0 chamado Píer de Ipanema.

O Píer de Ipanema foi instalado em 1970 em armações de ferro e madeira para a construção do emissário submarino e da rede coletora de esgoto do bairro e se tornou um ponto de encontro para muitos surfistas, pois a colocação da tubulação alterou a velocidade da água, provocando na região a formação de ondas violentas, ideais para a prática do surfe. Esse cenário se completava com as dunas artificiais, produzidas pela areia dragada do mar e despejada na praia por conta da construção do emissário.

As dunas se tornaram uma espécie de refúgio que acolheram muitos jovens, artistas e intelectuais envolvidos com os movimentos de contracultura. E para homenagear uma das musas da contracultura no Brasil e do Tropicalismo, elas ficaram conhecidas como as "dunas da Gal", em referência à cantora Gal Costa que morava na rua Farme de Amoedo em Ipanema e frequentava a praia exatamente neste trecho onde ficavam as famosas dunas, ou ainda, "dunas do Barato", em homenagem à música de Jards Macalé e Wally Salomão, Vapor Barato, em referência aos seus principais frequentadores, ao hábito do consumo de maconha, à juventude hippie e aos seus ideais alternativos de sociedade e de liberdade.

Lembramos que no final dos anos 1960 e ao longo dos 70, diversos movimentos de contestação contra a ordem política, econômica, social e cultural vigente se irradiaram pelo mundo. Nesse contexto, surgiram os movimentos de contracultura que tinham em comum o interesse de que o mundo fosse percebido de maneira subjetiva, a partir da expansão da consciência. Com isso, propunham a liberdade do sujeito e de suas ações. Por isso que, nesse período, uma série de revoluções no cotidiano das pessoas despontou na sociedade, como: o sexo livre e sem culpa; o consumo de drogas; o movimento feminista, dos homossexuais, e dos hippies; o uso de contraceptivos; da minissaia; do biquíni e da tanga. Esses movimentos sociais foram importantes para a crítica do status quo e para a promoção de uma vanguarda cultural e artística que afetou diretamente os costumes de uma época influenciando outras tantas gerações. Ipanema tornou-se, assim, polo difusor dessas manifestações.

De acordo com Daniel Aarão, os movimentos de contracultura defenderam e divulgaram novos valores e comportamentos sociais que se opuseram às preferências e às políticas dos poderes hegemônicos. Para o historiador, era uma crítica ao conservadorismo que ultrapassava o domínio estrito do discurso político do poder para alcançar as raízes do comportamento, das relações afetivas e da vida cotidiana. ${ }^{51}$

\footnotetext{
${ }^{50}$ VALLE, Marisol Rodriguez. A província da ousadia... Op. cit., p. 26-28.

${ }^{51}$ REIS FILHO, Daniel Aarão. 1968: a paixão de uma utopia. Rio de Janeiro: Espaço e Tempo, 1998, p. 20.
} 
Na dinâmica desse processo, é importante destacar que as drogas alucinógenas tiveram um significado todo especial. Primeiro porque ajudaram a vislumbrar essa nova realidade e depois porque o seu uso se atrevia contra à moral e aos padrões culturais burgueses até então hegemônicos no seio da sociedade brasileira. Essas drogas eram chamadas de psicodélicas. Para Luiz Carlos Maciel, jornalista d'O Pasquim e responsável pela coluna Underground no alternativo de Ipanema, a contracultura "forneceu à sua geração o sentido de um questionamento mais profundo da sociedade, do comportamento, do modo de viver, um questionamento que não se reduzia às intenções da revolução política tradicional". ${ }^{52}$ No artigo "Cultura de verão", Maciel (O Pasquim, de 1969) deu dicas de como se comportar na praia de Ipanema para os frequentadores iniciantes, assim esclareceu:

vai começar a temporada de verão na praia em frente à rua Montenegro e, por isso, me ofereço espontaneamente a dar alguns conselhos aos que tiverem se candidatando a frequentadores assíduos. Os visitantes vindos das províncias, principalmente, poderão aproveitá-los e evitar as mancadas vergonhosas. [...] Já tomei chopes e caipirinhas no Veloso suficientes para me conferir de certa autoridade. [...] É muito importante que você fale sobre drogas com absoluta displicência, mesmo que jamais tenha tomado nenhuma delas. Se já tomou, talvez seja mais difícil conter o entusiasmo, mas aguente firme. Você deve referir-se à maconha, principalmente, como se fosse Coca-Cola, tratando-a carinhosamente por fumo, para revelar o seu grau de intimidade. E procure deixar no ar que a maconha é até um troço meio devagar, que você já está em outra, na sua, etc. - e que a sua tem a ver com "ácido". Não dirija a palavra a quem não perceber, de cara, que o tal "ácido" é LSD. ${ }^{53}$

Para os cronistas Jaguar e Leonam, Ipanema deve ser observada não apenas como um bairro, mas como uma categoria que reunia valores e histórias de diferentes grupos, que com suas práticas sociais diárias modificaram a história da cidade e do país. ${ }^{54}$ Portanto, o que a princípio poderia representar uma simples expressão geográfica converteu-se em uma localidade com práticas sociais inovadoras, hábitos culturais de vanguarda e sentimentos que constituíram tradições em comum as quais foram apropriadas como parte da história do Rio de Janeiro e que foram projetadas para o Brasil, como uma referência nacional.

Dessa forma, percebemos que a identidade Ipanemense estava repleta de significados, rótulos ou marcas que expressaram ora uma vanguarda cultural ora uma alienação política. Por mais contraditório que possa parecer, tais marcas identificaram, e ainda identificam, os diferentes indivíduos que circularam por Ipanema e que representaram, a partir daquelas práticas cotidianas, o cenário múltiplo que se tornou o bairro, demarcando a sua história entre a Ipanema Provinciana e a Ipanema Cosmopolita.

Seja como for, a "República de Ipanema" deve ser compreendida como um grande mapa político-cultural da história da cidade do Rio de Janeiro, onde coexistiram diferentes grupos sociais e que promoveram várias revoluções cotidianas na sociedade. Esse espaço da cidade trouxe à tona transformações no comportamento, na moda, nas artes plásticas, no cinema, na música popular, na imprensa e em outras tantas atividades socioculturais, pois

\footnotetext{
52 MACIEL, Luís Carlos. As quatro estações. Rio de Janeiro: Record, 2001, p. 37.

53 MACIEL, Luís Carlos. Cultura de verão. O Pasquim, Rio de Janeiro, [1969].

54 JAGUAR. Ipanema: se não me falhe a memória. Rio de Janeiro: Relume-Dumará, 2000.
} 
daquele ambiente litorâneo foram divulgados novos hábitos sociais considerados tabus pela sociedade brasileira de um modo geral. Ipanema se tornou um marco na cultura nacional porque mudou o jeito, não somente do carioca, mas do brasileiro "escrever, falar, vestir-se (ou despir-se) e, possivelmente, de pensar". ${ }^{55}$

${ }^{55}$ CASTRO, Ruy. Ela é carioca... Op. cit., p. 11. 


\section{Referências}

ARGAN, Giulio Carlo. História da arte como história da cidade. São Paulo: Martins Fontes, 2005.

ARRUDA, Phrygia. O jeito carioca de ser: entre a tradição e a modernidade: o imaginário de um Brasil moderno. 2002. Tese (Doutorado em Psicologia) - Universidade Federal do Rio de Janeiro, Rio de Janeiro.

BAKHTIN, Mikhail. A cultura popular na Idade Média e no Renascimento: o contexto de François Rabelais. São Paulo: Hucitec, 1987.

BALSA, Marilene. Ipanema de rua em rua. Rio de Janeiro: Ed. Rio; Universidade Estácio de Sá, 2005.

CASTRO, Ruy. Ela é carioca: uma enciclopédia de Ipanema. São Paulo: Companhia das Letras, 1999.

FERNANDES, Millôr. [Entrevista]. EntreLivros, São Paulo, n. 5, p. 21-25, set. 2005.

FERNANDES, Millôr. A história é uma história: e o homem é único animal que ri. Porto Alegre: L\&PM, 1978.

HOLLANDA, Heloísa Buarque de; GONÇALVES, Marcos. Cultura e participação nos anos 60. São Paulo: Brasiliense, 1999.

JAGUAR. Confesso que bebi: memórias de um amnésico alcoólico. Rio de Janeiro: Record, 2001.

JAGUAR. Ipanema: se não me falhe a memória. Rio de Janeiro: Relume-Dumará, 2000.

KUCINSKI, Bernardo. Jornalistas e revolucionários: nos tempos da imprensa alternativa. São Paulo: EDUSP, 2003.

LEONAM, Carlos. Os degraus de Ipanema. Rio de Janeiro: Record, 1998.

MACIEL, Luís Carlos. As quatro estações. Rio de Janeiro: Record, 2001.

MACIEL, Luís Carlos. Cultura de verão. O Pasquim, Rio de Janeiro, [1969].

MESQUITA, Claudia. De Copacabana à Boca do Mato: o Rio de Janeiro de Sérgio Porto e Stanislaw Ponte Preta. Rio de Janeiro: Casa de Rui Barbosa, 2008.

MORAES, Vinícius de. Para viver um grande amor. Rio de Janeiro: José Olympio, 1984.

MOTTA, Marly. Rio, cidade-capital. Rio de Janeiro: Zahar, 2004.

NEVES, Margarida de Souza. História da crônica: crônica da história. In: RESENDE, Beatriz (org.). Cronistas do Rio. Rio de Janeiro: José Olympio, 1995, p. 15-31.

QUEIROZ, Andréa Cristina de Barros. Enfim, um escritor com estilo: o jornalista, pasquiniano, ipanemense e sem censura Millôr Fernandes. 2011. Tese (Doutorado em História Social) Universidade Federal do Rio de Janeiro, Rio de Janeiro.

QUEIROZ, Andréa Cristina de Barros. O Pasquim: um jornal que só diz a verdade quando está sem imaginação (1969-1991). 2005. Dissertação (Mestrado em História) - Universidade Federal Fluminense, Niterói (RJ).

RAMA, Angel. A cidade das letras. Rio de Janeiro: Brasiliense, 1985.

REGO, Norma Pereira. Ipanema dom divino. Rio de Janeiro: Nova Fronteira, 1983. 
REGO, Norma Pereira. Pasquim: gargalhantes pelejas. Rio de Janeiro: Relume-Dumará, 1996. REIS FILHO, Daniel Aarão. 1968: a paixão de uma utopia. Rio de Janeiro: Espaço e Tempo, 1998.

RESENDE, Beatriz (org.). Cronistas do Rio. Rio de Janeiro: José Olympio, 1995.

RITO, Lúcia; SOUZA, Jair de (org.). Zona norte: território da alma carioca. Rio de Janeiro: Norte Shopping, 2001.

ROEDEL, Hiran. Uma cidade de muitos lugares. In: VIEIRA, A. da C. (org.). Rio de Janeiro: panorama sociocultural. Rio de Janeiro: Ed. Rio, 2004, p.18-55.

SABINO, Fernando. Livro aberto. Rio de Janeiro: Record, 2001.

VALLE, Marisol Rodriguez. A província da ousadia: representações sociais sobre Ipanema, 2005. Dissertação (Mestrado) - Programa de Pós-Graduação em Sociologia e Antropologia. Rio de Janeiro: UFRJ, 2005.

VELHO, Gilberto. Nobres e anjos: um estudo sobre tóxicos e hierarquia. Rio de Janeiro: FGV Ed., 1998. 